\title{
ANALISIS SISTEM PENYEDIAAN PEMESANAN DAN PELEKATAN PITA CUKAI MINUMAN MENGANDUNG ETIL ALKOHOL PADA KANTOR PENGAWASAN DAN PELAYANAN BEA CUKAI MANADO
}

\author{
Yuliastri Makalare $^{1}$, Ventje Ilat ${ }^{2}$, Rudy Pusung $^{3}$ \\ ${ }^{1,2,3}$ Fakultas Ekonomi dan Bisnis. Jurusan Akuntansi. Universitas Sam Ratulangi, Jl. Kampus Bahu, Manado, \\ 95115, Indonesia. \\ E-mail :makalarejulyastri@gmail.com
}

\begin{abstract}
Excise is a state levy imposed on certain goods which have properties or characteristics established in law. In 2013 the Ministry of Finance of the Directorate General of Customs and Excise changed the monitoring system to MMEA which is to change the way of excise tax from payment to sticking the excise tape by issuing the provisions on sticking the excise band against MMEA. The purpose of this study is to find out whether the MMEA customs declaration, ordering and sticking procedure is in conformity with the prevailing regulations and whether the MMEA monitoring system that has changed can improve the monitoring of MMEA. The analytical method used is descriptive describing the procedure of service provision, ordering, and sticking of excise band of MMEA. The results show that the procedures applied are in accordance with the rules that apply although still have some obstacles in terms of implementation and supervision. Approximately 6,924 bottles of MMEA have no production license, no excise band, using fake excise bands, using used excise tape, using excise duty tape, using excise tape which is incompatible with the type and class and making MMEA containing hazardous materials For humans. Therefore it is expected KPPBC Manado City maximizes the implementation of supervision and control system in force.
\end{abstract}

Keywords: Keywords: sticking Excise tape, MMEA, Supervision.

\section{PENDAHULUAN}

Pembangunan Nasional merupakan pembangunan yang dapat diharapkan untuk meningkatkan kesejahteraan dan kemakmuran masyarakat. Pembangunan yang ingin dicapai bangsa Indonesia adalah mewujudkan masyarakat adil dan makmur yang merata baik materil maupun spritual berdasarkan pancasila dan Undang-Undang Dasar 1945. Dalam usaha mencapai tujuan pembangunan nasional tersebut, pemerintah menciptakan tahap-tahap pelaksanaannya, baik untuk jangka panjang maupun jangka pendek yang meliputi perencanaan, pelaksanaan, pembiayaan, pengawasan, pembentukan, dan evaluasi dengan tidak mengecilkan arti peran dari pihak-pihak lainnya maupun berpartisipasi mensukseskan pembangunan nasional, karena membutuhkan anggaran yang cukup besar dalam merealisasikan tujuan tersebut.

Sistem Pengawasan dan Pengendalian yang telah dibuat oleh pemerintah khususnya Direktorat Jenderal Bea dan Cukai adalah pelekatan pita cukai pada Barang Kena cukai Tembakau yang sudah banyak beredar di masyarakat, sedangkan pada etil Alkohol dan MMEA hanya melakukan pelunasan pembayaran cukai pada saat barang dikeluarkan..

Kebijakan pelekatan pita cukai pada MMEA buatan dalam negeri hanya dilakukan pada MMEA dengan kadar Alkohol lebih dari 5\% atau termasuk dalam golongan B dan C. Sedangkan pada MMEA asal impor harus dilekatkan pita cukai pada kadar alkohol 
berapapun. Dalam mengoptimalkan kebijakan yang telah dibuat, Direktorat Jenderal Bea dan Cukai mengeluarkan peraturan PER-24/BC/2015 tentang Penyediaan dan Pemesan Pita cukai yang menjelaskan tentang prosedur penyediaan dan pemesanan serta hal-hal terkait persiapan dokumen penyediaan pita cukai. Tujuan dibuatnya peraturan tersebut agar pengusaha dan kantor pemungut cukai dapat bertukar informasi berupa data elektronik terkait produksi Barang Kena Cukai..

Di Kota Manado terdapat 13 pabrik yang memproduksi MMEA, Ketiga belas pabrik tersebut berada dalam pengawasan yang ketat KPPBC Tipe Madya Cukai Kota Manado. DJBC melalui KPPBC Tipe Madya CukaMalang selain bertugas untuk melayankepabeanan dan cukai juga bertugas untukmengawasi dan memastikan pengusaha MMEAdi Kota Malang telah patuh pada UU Cukai yang berlaku, terutama bagi pelaku usaha MMEA buatan dalam negeri. Jika terjadi pelanggaran, maka KPPBC Tipe Madya Cukai kota Manado wajib menindaknya sesuai dengan hukum yang berlaku. Namun, terdapat beberapa kendala yang dirasakan oleh KPPBC Tipe Madya Cukai Kota Manado dalam melaksanakan kebijakan tersebut, Sehingga menyebabkan masih terdapat beberapa pelanggaran yang masih perlu penindakan yang lebih dari pihak KPPBC Tipe Madya Cukai Kota Manado. Adapun tujuan yang ingin dicapai dalam penelitian ini Untuk Menganalisis apakah Sistem Penyediaan, Pemesanan dan Pelekatan Pita Cukai Minuman Mengandung Etil Alkohol Pada Kantor Pengawasan Dan Pelayanan Bea Cukai Manado sudah sesuai dengan aturan yang berlaku dan sudah memberikan dampak yang baik bagi sistem Pengawasan dan Pengendalian terhadap Pengusaha MMEA.

\section{TINJAUAN PUSTAKA}

\subsection{Konsep Akuntansi Pajak}

Menurut Djoko Muljono (2014 : 3), menyatakan bahwa Akuntansi Pajak adalah bidang akuntansi yang berkaitan dengan perhitungan perpajakan, yang mengacu pada peraturan, undang-undang, dan aturan pelaksanaan perpajakan.

\subsection{Konsep Perpajakan}

\section{Definisi Pajak}

Definisi pajak menurut Undang-Undang (UU) Pajak Nomor 28 tahun 2007 menyatakan pajak adalah kontribusi wajib kepada negara yang bersifat memaksa berdasarkan UU dengan tidak mendapatkan imbalan secara langsung dan digunakan untuk keperluan negara demi kemakmuran dan kesejahteraan rakyat.

\section{Fungsi Pajak}

Menurut Mardiasmo (2016:1) pajak mempunyai beberapa fungsi, yaitu:

1. Fungsi Anggaran (Budgeter)

2. Fungsi Mengatur (Regulerend)

\subsection{Konsep Cukai \\ Definisi Cukai}

Berdasarkan UU No. 39 Tahun 2007 mendefinisikan Cukai adalah pungutan negara yang dikenakan terhadap barang-barang tertentu yang mempunyai sifat atau karakteristik yang ditetapkan dalam undang-undang. Purwito (2014 : 408) mendefinisikan cukai merupakan pungutan negara yang berbentuk pajak tidak langsung yang dibayarkan atas pembelian barang yang spesifik yang sering disebut dengan barang kena cukai.

\section{Fungsi Dan Tujuan Cukai}


Menurut Surono (2012) Bila ditinjau dari sisi maksud dan tujuan pemungutan, cukai dapat digunakan sebagai alat fiskal pemerintah dalam rangka menarik dana dari masyarakat untuk membiayai pengeluaran pemerintah. Disisi lain tujuan cukai juga dapat diarahkan untuk kepentingan pengaturan (regulerend) dalam rangka mencapai maksud-maksud tertentu yang diinginkan pemerintah, antara lain pembatasan produk yang berdampak negatif, pembatasan peredaran, kompensasi biaya eksternalitas, asas keadilan, dan keseimbangan.

\section{Subjek Dan Objek Cukai}

Pancapuri (2014), Subjek cukai adalah orang atau badan hukum yang bertanggung jawab atas pungutan cukai. dalam undang-undang cukai No. 39 Tahun 2007 subjek cukai yang dimaksud adalah:

a. Pengusaha Pabrik Barang Kena Cukai

b. Pengusaha Tempat Penyimpanan Etil Alkohol

c. Importir Barang Kena Cukai

d. Penyalur Etil Alkohol

e. Pengusaha Tempat Penjualan Eceran Etil Alkohol.

Penggolongan Cukai Minuman Beralkohol Buatan Dalam Negeri

Berdasarkan PMK No. 62/PMK.011/2010, cukai minuman beralkohol terdiri dari 3 golongan sesuai kadar alkohol yang terkandung yaitu sebagai berikut.

1. Kadar sampai dengan $5 \%$, termasuk dalam golongan A

2. Kadar $5 \%$ sampai dengan $20 \%$, termasuk dalam golongan B

3. Kadar diatas $20 \%$, termasuk dalam golongan $\mathrm{C}$.

\section{Tarif Pemungutan Cukai Minuman Mengandung Etil Alkohol}

Sehubungan dengan kebijakan tarif cukai Minuman Yang Mengandung Etil Alkohol (MMEA) tahun 2014, Menteri Keuangan menetapkan Peraturan Menteri Keuangan (PMK) Nomor 207/PMK.011/2013 tentang Perubahan atas PMK Nomor 62/PMK.011/2010 tentang Tarif Cukai Etil Alkohol, Minuman Yang Mengandung Etil Alkohol, dan Konsentrat Yang Mengandung Etil Alkohol pada tanggal 31 Desember 2013, dengan ketentuan tarif cukainya mulai berlaku pada tanggal 1 Januari 2014. Kenaikan tarif cukai diterapkan untuk semua golongan MMEA, yaitu MMEA golongan A (kadar alkohol 5\%), golongan B (>5\% s.d. $\sim 20 \%$ ), dan golongan C (>20\%) dinaikkan secara moderat berkisar mulai Rp 2.000,- s.d. Rp 9.000,- per liter dengan rata-rata kenaikan sekitar 11,66\% (sebelas koma enam puluh enam persen).

\subsection{Penelitian Terdahulu}

1. Ismitania (2012) dengan judul Analisis Pelekatan Pita Cukai MMEA buatan dalam negeri. Tujuan penelitian menganalisis sistem pengawasan yang dilakukan oleh DJBC dari pembayaran cukai ke pelekatan pita cukai. Metode yang digunakan Deskriptif kualitatif. Hasil peneltian menunjukan pelaksanaan pelekatan pita cukai sangat membantu DJBC dalam mengawasi MMEA yang beredar dimasyarakat namun masih banyak yang harus diperbaiki.

2. Rahadian (2015) dengan judul Evaluasi Kebijakan Pengawasan Pelekatan Pita Cukai Pada Minuman Mengandung Etil Alkohol (MMEA) Buatan Dalam Negeri Pada Kantor KPPBC Malang. Tujuan penelitian mengevaluasi prosedur pelekatan pita cukai pada MMEA buatan dalam negeri. Metode yang digunakan Deskriptif Kualitatif. Hasil penelitian menunjukan penerimaan dari cukai pada DJBC Malang sudah memenuhi target namun 
masih terdapat beberapa pelanggran dalam prosedur pelekatan pita cukai MMEA buatan dalam negeri pada KPPBC Malang.

\section{METODE PENELITIAN}

\subsection{Jenis Penelitian}

Jenis Penelitian yang digunakan oleh penulis adalah deskriptif. Menurut Sugiyono (2015:147) menyatakan bahwa: "Metode deskriptif adalah metode yang digunakan untuk mendeskripsikan atau menggambarkan data yang telah terkumpul sebagaimana adanya tanpa bermaksud membuat kesimpulan yang berlaku untuk umum atau generalisasi”.

\subsection{Tempat dan Waktu Penelitian}

Tempat yang dipilih untuk melakukan penelitian adalah Kantor Pengawasan dan Pelayanan Bea Cukai Kota Manado, JL. A.A. Maramis , Paniki Bawah, Mapanget. Dengan waktu penelitian dari tanggal 20 April 2017 - 25 Mei 2017.

\subsection{Metode Pengumpulan Data \\ Jenis Data}

Data adalah sekumpulan informasi yang diperlukan untuk pengambilan keputusan (Kuncoro, 2011)

\section{Data Kualitatif}

Kualitatif menurut Sugiyono (2015 : 148) adalah penelitian yang digunakan untuk meneliti pada kondisi objek yang alamiah, dimana peneliti ini adalah sebagai instrument kunci, teknik pengumpulan data dilakukan secara induktif, dan hasil penelitian kualitatif lebih menekankan makna daripada generalisasi. Objek alamiah yang dimaksud adalah objek yang apa adanya, tidak dimanipulasi oleh peneliti sehingga kondisi pada saat peneliti memasuki objek, setelah berada di objek dan setelah keluar dari objek relatif tidak berubah.

\section{Sumber Data}

Sumber primer adalah sumber data yang secara langsung memberikan data kepada pengumpul data (Sugiyono, 2015:225). Sumber primer ini berupa catatan hasil wawancara yang diperoleh melalui wawancara dengan pihak Pegawai di Kantor Pengawasan dan Pelayanan Bea Cukai Kota Manado, yang akan dilakukan oleh peneliti.

Menurut Fathoni (2011: 38), data sekunder merupakan data yang diperoleh dari literatur-literatur serta tulisan-tulisan yang berhubungan dengan penelitian ini. Sumber data yang digunakan dalam penelitian ini juga berasal dari dokumen-dokumen prosedur Penyediaan, Pemesanan dan pelekatan pita cukai minuman mengandung etil alkohol di Kantor Pengawasan dan Pelayanan Bea Cukai Kota Manado.

\section{Teknik Pengumpulan Data}

1. Wawancara

2. Dokumentasi

\subsection{Metode Analisis}

Metode analisis yang digunakan dalam penelitian ini adalah metode deskriptif yang dimaksud untuk menggambarkan objek yang diteliti dan mengetahui tentang prosedur penyediaan, pemesanan dan pelekatan pita cukai minuman mengandung etil alkohol serta menguraikan data-data yang diperoleh dari KPPBC Kota Manado. Data tersebut kemudian 
dibandingkan dengan landasan teori yang ada dan dilakukan pembahasan masalah sehingga bisa ditarik kesimpulan mengenai prosedur penyediaan, pemesanan dan pelekatan pita cukai minuman mengandung etil alkohol pada KPPBC Kota Manado.

\section{HASIL ANALISIS DAN PEMBAHASAN}

\subsection{Hasil Penelitian}

Analisis Sistem Penyediaan, Pemesanan dan Pelekatan Pita Cukai MMEA

Dibawah ini merupakan tabel perbandingan sistem penyediaan, pemesanan dan pelekatan pita cukai Minuman Mengandung Etil Alkohol berdasarkan Peraturan Nomor PER24/BC/2015, PER-45/BC/2016, dan PER-23/BC/2015 dengan Standar Operasional Prosedur yang ada pada KPPBC Kota Manado.

Tabel. 1 Perbandingan Peraturan Penyediaan Pita Cukai MMEA

\begin{tabular}{|c|c|c|c|}
\hline NO & PER-24/BC/2015 & SOP yang berlaku & Keterangan \\
\hline 1 & $\begin{array}{c}\text { Pengusaha wajib } \\
\text { mengajukan P3C MMEA } \\
\text { kepada Kepala Kantor }\end{array}$ & $\begin{array}{c}\text { Mengajukan P3C kepada } \\
\text { kepala kantor melalui pejabat } \\
\text { penerima dokumen pada seksi } \\
\text { perbendaharaan di kantor bea } \\
\text { dan cukai }\end{array}$ & Sesuai \\
\hline 2 & $\begin{array}{l}\text { Kepala Kantor meneruskan } \\
\text { P3C ke kantor pusat }\end{array}$ & $\begin{array}{c}\text { Pejabat Penerima Dokumen } \\
\text { pada Seksi Perbendaharaan } \\
\text { merekam data P3C di Sistem } \\
\text { Aplikasi Cukai dan } \\
\text { membandingkan pengisian } \\
\text { hard copy P3C dengan data } \\
\text { P3C yang telah direkam. } \\
\text { Kemudian ketika telah sesuai } \\
\text { disetujui oleh kepala kantor, } \\
\text { lalu diteruskan kekantor pusat }\end{array}$ & Sesuai \\
\hline
\end{tabular}

Sumber : Data diolah 2016

Tabel 2 Perbandingan Peraturan Pemesanan Pita Cukai MMEA

\begin{tabular}{|c|c|c|c|}
\hline NO & PER-45/BC/2015 & SOP yang berlaku & Keterangan \\
\hline 1 & $\begin{array}{c}\text { Proses Pendaftaran: } \\
\text { Pengusaha Mengisi format CK- } \\
\text { 1/CK-1A dengan lengkap } \\
\text { sesuai ketentuan, termasuk } \\
\text { penggunaan CK-2 dan/atau } \\
\text { CK-3 untuk kompensasi cukai, } \\
\text { kompensasi Pajak Pertambahan } \\
\text { Nilai MMEA, dan } \\
\text { menyerahkan kepada Pejabat } \\
\text { Penerima Dokumen. }\end{array}$ & $\begin{array}{c}\text { Proses Pendaftaran: } \\
\text { Pengusaha Mengisi format } \\
\text { CK-1/CK-1A dengan lengkap } \\
\text { sesuai ketentuan, termasuk } \\
\text { penggunaan CK-2 dan/atau } \\
\text { CK-3 untuk kompensasi cukai, } \\
\text { kompensasi Pajak } \\
\text { Pertambahan Nilai MMEA, } \\
\text { dan menyerahkan kepada } \\
\text { Pejabat Penerima Dokumen. }\end{array}$ & Sesuai \\
\hline
\end{tabular}




\begin{tabular}{|c|c|c|c|}
\hline NO & PER-45/BC/2015 & SOP yang berlaku & Keterangan \\
\hline 2 & $\begin{array}{l}\text { CK-1A paling sedikit rangkap } 2 \\
\text { (dua) ke Kantor, dengan rincian } \\
\quad \text { sebagai berikut : } \\
\text { a. Rangkap pertama untuk } \\
\text { Kantor } \\
\text { b. Rangkap kedua untuk } \\
\\
\text { Pengusaha }\end{array}$ & $\begin{array}{l}\text { CK-1A paling sedikit rangkap } \\
2 \text { (dua) ke Kantor, dengan } \\
\text { rincian sebagai berikut : } \\
\text { c. Rangkap pertama untuk } \\
\text { Kantor } \\
\text { d. Rangkap kedua untuk } \\
\text { Pengusaha }\end{array}$ & Sesuai \\
\hline 3 & 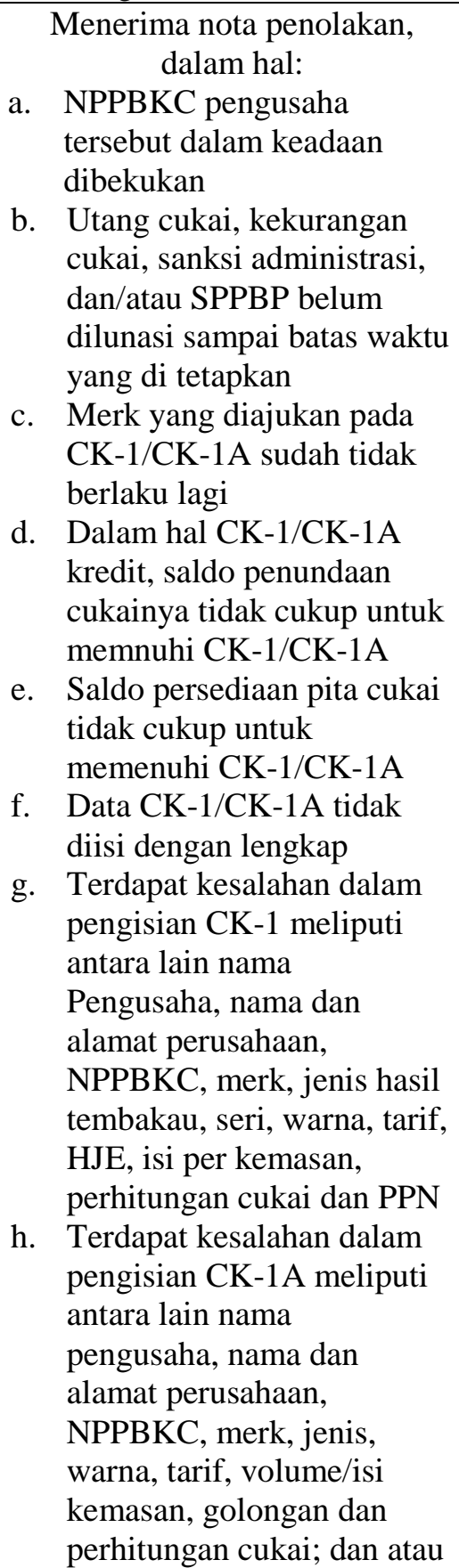 & 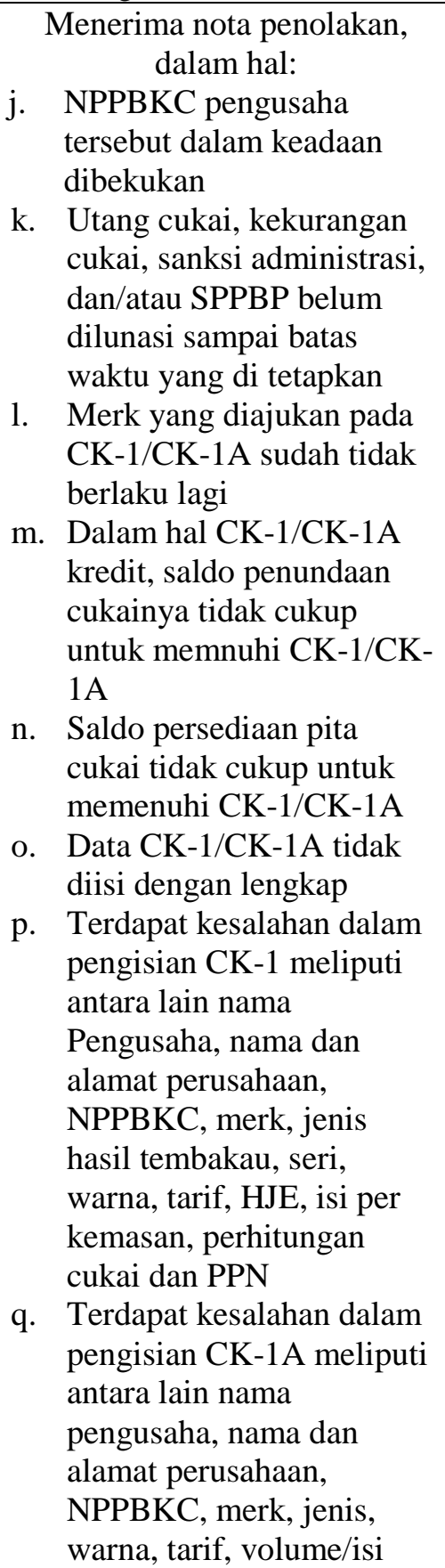 & Sesuai \\
\hline
\end{tabular}




\begin{tabular}{|c|c|c|c|}
\hline NO & PER-45/BC/2015 & SOP yang berlaku & Keterangan \\
\hline & $\begin{array}{ll}\text { i. } & \text { Saldo CK-2/CK-3 tidak } \\
\text { mencukupi untuk } \\
\text { digunakan sebagai } \\
\text { kompensasi cukai }\end{array}$ & $\begin{array}{ll} & \text { kemasan, golongan dan } \\
\text { perhitungan cukai; dan } \\
\text { atau } \\
\text { r. } & \text { Saldo CK-2/CK-3 tidak } \\
\text { mencukupi untuk } \\
\text { digunakan sebagai } \\
\text { kompensasi cukai }\end{array}$ & \\
\hline 4 & $\begin{array}{l}\text { Mengajukan kembali CK-1A } \\
\text { setelah dilengkapi/diperbaiki }\end{array}$ & $\begin{array}{l}\text { Mengajukan kembali CK-1A } \\
\text { setelah dilengkapi/diperbaiki }\end{array}$ & Sesuai \\
\hline 5 & $\begin{array}{c}\text { Menerima tanda terima CK-1A } \\
\text { dalam hal data CK-1A telah } \\
\text { lengkap }\end{array}$ & $\begin{array}{c}\text { Menerima tanda terima CK- } \\
\text { 1A dalam hal data CK-1A } \\
\text { telah lengkap }\end{array}$ & Sesuai \\
\hline 6 & $\begin{array}{l}\text { Memeriksa dan mencocokkan } \\
\text { data CK-1A dengan data yang } \\
\text { tertera pada tanda terima }\end{array}$ & $\begin{array}{c}\text { Memeriksa dan mencocokkan } \\
\text { data CK-1A dengan data yang } \\
\text { tertera pada tanda terima }\end{array}$ & Sesuai \\
\hline 7 & $\begin{array}{l}\text { Menandatangani tanda terima } \\
\text { CK-1A dalam hal data CK-1A } \\
\text { dan data yang tertera pada } \\
\text { tanda terima telah sesuai }\end{array}$ & $\begin{array}{l}\text { Menandatangani tanda terima } \\
\text { CK-1 A dalam hal data CK-1A } \\
\text { dan data yang tertera pada } \\
\text { tanda terima telah sesuai }\end{array}$ & Sesuai \\
\hline 8 & $\begin{array}{l}\text { Menyerahkan tanda terima CK- } \\
\text { 1A untuk mendapatkan nomor } \\
\text { CK-1A kepada Pejabat pada } \\
\text { Seksi Pabean dan Cukai }\end{array}$ & $\begin{array}{c}\text { Menyerahkan tanda terima } \\
\text { CK-1A untuk mendapatkan } \\
\text { nomor CK-1A kepada Pejabat } \\
\text { pada Seksi Pabean dan Cukai }\end{array}$ & Sesuai \\
\hline 9 & $\begin{array}{c}\text { Menyimpan tanda terima CK- } \\
1 \mathrm{~A}\end{array}$ & $\begin{array}{l}\text { Menyimpan tanda terima CK- } \\
1 \mathrm{~A}\end{array}$ & Sesuai \\
\hline 10 & $\begin{array}{c}\text { Menerima CK-1A rangkap } \\
\text { kedua dari Pejabat pada Seksi } \\
\text { Pabean dan Cukai }\end{array}$ & $\begin{array}{c}\text { Menerima CK-1A rangkap } \\
\text { kedua dari Pejabat pada Seksi } \\
\text { Pabean dan Cukai }\end{array}$ & Sesuai \\
\hline 11 & $\begin{array}{c}\text { Dalam hal pembayaran } \\
\text { menggunakan Kode Billing, } \\
\text { menerima struk Billing dari } \\
\text { Pejabat pada Seksi Pabean dan } \\
\text { Cukai }\end{array}$ & $\begin{array}{c}\text { Dalam hal pembayaran } \\
\text { menggunakan Kode Billing, } \\
\text { menerima struk Billing dari } \\
\text { Pejabat pada Seksi Pabean dan } \\
\text { Cukai }\end{array}$ & Sesuai \\
\hline 12 & \begin{tabular}{|ll} 
& Dalam hal diperlukan \\
& pembatalan CK-1A: \\
a. & Mengajukan surat \\
& permohonan pembatalan \\
& CK-1A kepada Kantor \\
b. & Menerima nota pembatalan \\
& CK-1A
\end{tabular} & $\begin{array}{ll} & \text { Dalam hal diperlukan } \\
& \text { pembatalan CK-1A: } \\
\text { c. } & \text { Mengajukan surat } \\
& \text { permohonan pembatalan } \\
& \text { CK-1A kepada Kantor } \\
\text { d. } & \text { Menerima nota pembatalan } \\
& \text { CK-1A }\end{array}$ & Sesuai \\
\hline
\end{tabular}




\begin{tabular}{|c|c|c|c|}
\hline NO & PER-45/BC/2015 & SOP yang berlaku & Keterangan \\
\hline 13 & \begin{tabular}{l} 
Dalam hal CK-1A dengan \\
\multicolumn{1}{c}{ kredit : } \\
a. \\
Menyerahakan jaminan \\
kepada Subseksi \\
Perbendaharaan dan \\
Pelayanan \\
b. \\
Menerima bukti \\
penerimaan jaminan (BPJ)
\end{tabular} & \begin{tabular}{ll} 
& \multicolumn{1}{|c}{ Dalam hal CK-1A dengan } \\
& \multicolumn{1}{c}{ kredit : } \\
c. & Menyerahakan jaminan \\
& kepada Subseksi \\
& Perbendaharaan dan \\
& Pelayanan \\
d. & Menerima bukti \\
& penerimaan jaminan (BPJ)
\end{tabular} & sesuai \\
\hline 14 & $\begin{array}{c}\text { Proses Pelunasan: } \\
\text { Untuk CK-1A tunai: } \\
\text { a.Dalam hal pembayaran } \\
\text { menggunakan Kode Billing. } \\
\text { dengan Kode Billing, } \\
\text { melakukan pembayaran cukai } \\
\text { dan pungutan negara lainnya ke } \\
\text { Bank Persepsi/Pos Persepsi } \\
\text { melalui berbagai media } \\
\text { pembayaran yang } \\
\text { dimungkinkan, pada tanggal } \\
\text { yang sama dengan tanggal yang } \\
\text { sama dengan tanggal CK-1A } \\
\text { tunai } \\
\text { b.Dalam hal pembayaran } \\
\text { menggunakan SSPCP: } \\
\text { Melakukan pembayaran cukai } \\
\text { dan pungutan negara lainnya ke } \\
\text { Bank Persepsi/Pos Persepsi } \\
\text { dengan membawa SSPCP, pada } \\
\text { tanggal yang sama dengan } \\
\text { tanggal CK-1A tunai } \\
\text { Menyerahkan CK-1A rangkap } \\
\text { kedua dan SSPCP kepada } \\
\text { Pejabat pada Seksi Penerimaan } \\
\text { dan Pengembalian }\end{array}$ & $\begin{array}{c}\text { Proses Pelunasan : } \\
\text { Untuk CK-1A tunai: } \\
\text { a.Dalam hal pembayaran } \\
\text { menggunakan Kode Billing. } \\
\text { dengan Kode Billing, } \\
\text { melakukan pembayaran cukai } \\
\text { dan pungutan negara lainnya } \\
\text { ke Bank Persepsi/Pos Persepsi } \\
\text { melalui berbagai media } \\
\text { pembayaran yang } \\
\text { dimungkinkan, pada tanggal } \\
\text { yang sama dengan tanggal } \\
\text { yang sama dengan tanggal } \\
\text { CK-1A tunai } \\
\text { b.Dalam hal pembayaran } \\
\text { menggunakan SSPCP: } \\
\text { Melakukan pembayaran cukai } \\
\text { dan pungutan negara lainnya } \\
\text { ke Bank Persepsi/Pos Persepsi } \\
\text { dengan membawa SSPCP, } \\
\text { pada tanggal yang sama } \\
\text { dengan tanggal CK-1A tunai } \\
\text { Menyerahkan CK-1A rangkap } \\
\text { kedua dan SSPCP kepada } \\
\text { Pejabat pada Seksi Penerimaan } \\
\text { dan Pengembalian }\end{array}$ & Sesuai \\
\hline 15 & $\begin{array}{l}\text { Melakukan pengambilan pita } \\
\text { cukai dikantor KPPBC Kota } \\
\text { Manado dengan } \\
\text { memperlihatkan tanda pengenal }\end{array}$ & $\begin{array}{c}\text { Melakukan pengambilan pita } \\
\text { cukai dikantor KPPBC Kota } \\
\text { Manado dengan } \\
\text { memperlihatkan tanda } \\
\text { pengenal }\end{array}$ & Sesuai \\
\hline 16 & $\begin{array}{c}\text { Dalam hal pengurusan CK-1A } \\
\text { dilakukan oleh kuasa, } \\
\text { menyampaikan surat kuasa } \\
\text { kepada KPPBC Kota Manado } \\
\text { dan Kepada Kantor Pusat } \\
\text { apabila pita cukai disediakan di } \\
\text { Kantor Pusat, setiap tahun } \\
\text { sebelum pengajuan CK-1A }\end{array}$ & $\begin{array}{c}\text { Dalam hal pengurusan CK-1A } \\
\text { dilakukan oleh kuasa, } \\
\text { menyampaikan surat kuasa } \\
\text { kepada KPPBC Kota Manado } \\
\text { dan Kepada Kantor Pusat } \\
\text { apabila pita cukai disediakan } \\
\text { di Kantor Pusat, setiap tahun } \\
\text { sebelum pengajuan CK-1A }\end{array}$ & Sesuai \\
\hline
\end{tabular}




\begin{tabular}{|l|c|c|c|}
\hline NO & PER-45/BC/2015 & SOP yang berlaku & Keterangan \\
\hline 17 & pertama pada tahun berjalan & pertama pada tahun berjalan & \\
\hline $\begin{array}{c}\text { Menerima pita cukai dan CK- } \\
\text { tanda terima pita cukai dan CK- } \\
1 \text { A }\end{array}$ & $\begin{array}{c}\text { Menerima pita cukai dan CK- } \\
\text { 1A dari KPPBC Kota Manado, } \\
\text { tanda terima pita cukai dan } \\
\text { CK-1A }\end{array}$ & Sesuai \\
\hline 18 & $\begin{array}{c}\text { Mencocokkan jenis dan jumlah } \\
\text { pita cukai yang diterima dengan } \\
\text { data yang tertera dalam CK-1A }\end{array}$ & $\begin{array}{c}\text { Mencocokkan jenis dan } \\
\text { jumlah pita cukai yang } \\
\text { diterima dengan data yang } \\
\text { tertera dalam CK-1A }\end{array}$ & Sesuai \\
\hline 19 & $\begin{array}{c}\text { Menandatangani CK-1A } \\
\text { halaman kedua carik II dan } \\
\text { tanda terima pita cukai sebagai } \\
\text { bukti telah menerima pita cukai } \\
\text { dengan lengkap }\end{array}$ & $\begin{array}{c}\text { Menandatangani CK-1A } \\
\text { halaman kedua carik II dan } \\
\text { tanda terima pita cukai sebagai } \\
\text { bukti telah menerima pita } \\
\text { cukai dengan lengkap }\end{array}$ & Sesuai \\
\hline 20 & $\begin{array}{c}\text { Mengembalikan CK-1A kepada } \\
\text { KPPBC Kota Manado atau } \\
\text { Kantor Pusat; }\end{array}$ & $\begin{array}{c}\text { Mengembalikan CK-1A } \\
\text { kepada KPPBC Kota Manado } \\
\text { atau Kantor Pusat; }\end{array}$ & Sesuai \\
\hline 21 & $\begin{array}{c}\text { Menyimpan CK-1A rangkap } \\
\text { kedua dan tanda terima pita } \\
\text { cukai }\end{array}$ & $\begin{array}{c}\text { Menyimpan CK-1A rangkap } \\
\text { kedua dan tanda terima pita } \\
\text { cukai }\end{array}$ & Sesuai \\
\hline
\end{tabular}

Sumber : Data diolah 2016

\subsubsection{Analisis Sistem Penyediaan, Pemesanan dan Pelekatan Pita Cukai MMEA terhadap Sistem Pengawasan dan Pengendalian}

Menurut kepala seksi perbendaharaan sistem pengawasan yang diterapkan akan terus dimaksimalkan, mengingat sampai akhir tahun 2016 masih terdapat 6.924 (enam ribu Sembilan ratus dua puluh empat) botol MMEA yang ditegahkan atau dimusnahkan karena Barang kena cukai tersebut dinyatakan illegal. Minuman Mengandung Etil Alkohol dinyatakan illegal, karena antara lain dibuat dengan tidak memiliki izin produksi, tanpa pita cukai, menggunakan pita cukai palsu, menggunakan pita cukai bekas, menggunakan pita cukai yang bukan haknya, menggunakan pita cukai yang tidak sesuai dengan jenis dan golongannya serta membuat MMEA yang mengandung bahan-bahan yang berbahaya bagi manusia. Tentu hal ini sangat merugikan Negara karena menghambat pertumbuhan ekonomi dengan tidak patuh kepada aturan yang berlaku.

\section{KESIMPULAN DAN SARAN}

\subsection{Kesimpulan}

Berdasarkan beberapa uraian yang telah dikemukakan, maka penulis menarik kesimpulan sebagai berikut :

1. Prosedur Penyediaan, Pemesanan dan Pelekatan Pita Cukai MMEA pada KPPBC Kota Manado sudah sesuai dengan Peraturan Direktorat Jenderal Bea Cukai yang 
berlaku namun masih terdapat beberapa kekurangan dalam pelayanan teknis yaitu masih banyak prosedur pelayanan yang belum dipahami oleh pengusaha MMEA.

2. Sistem Pengawasan dan Pengendalian dalam penyediaan, pemesanan dan pelekatan pita cukai belum begitu baik karena masih terdapat 6.924 (enam ribu Sembilan ratus dua puluh empat) botol MMEA dinyatakan illegal, karena antara lain dibuat dengan tidak memiliki izin produksi, tanpa pita cukai, menggunakan pita cukai palsu, menggunakan pita cukai bekas, menggunakan pita cukai yang bukan haknya, menggunakan pita cukai yang tidak sesuai dengan jenis dan golongannya serta membuat MMEA yang mengandung bahan-bahan yang berbahaya bagi manusia.

\subsection{Saran}

Berdasarkan kesimpulan yang ada penulis ingin memberikan beberapa saran yang membangun bagi Kantor Pengawasan dan Pelayanan Bea Cukai Kota Manado, agar kiranya teknis pelaksanaan permohonan penyediaan, pemesanan dan pelekatan pita cukai dibuat lebih sederhana dan dalam jangka waktu yang cepat dan efektif agar para pengusaha MMEA tidak memiliki alasan apapun untuk menghindari membayar bea cukai. Dalam segi pengawasan terhadap penyalahgunaan peraturan pelekatan pita cukai, agar supaya lebih dimaksimalkan dalam hal penindakan pemberian sanksi kepada pengusaha yang melakukan pelanggaran serta lebih intens dalam hal pemeriksaan lapangan diperusahaan-perusahaan yang memproduksi MMEA.

\section{DAFTAR PUSTAKA}

Aristanti, Widyaningsih. 2011. Hukum Pajak dan Perpajakan. Bandung : ALFABETA.

Doanna Novianti, 2014. Analisis Tingkat Produksi Dan Pungutan Cukai Minuman Beralkohol Pada Pabrik Anggur Capung Palembang. STIE MDP, Palembang

Emmanuel Umeora, 2016. The Effects of Value Added Tax (VAT) on the Economic Growth of Nigeria. Journal of Economics and Sustainable Development Vol.4, No.6,

Faresz, 2016. Evaluasi pelaksanaan dan pemungutan cukai minuman beralkohol buatan dalam negeri berdasarkan per-01/bc/2014 dan per-24/bc/2015 pada kantor pengawasan dan pelayanan bea dan cukai tipe pabean c manado. Jurnal Emba Volume 4 No. 4

GASB Concepts Statement No. 1, Objectives of Financial Reporting: 62-68)

IARD Policy Review, 2017. Taxation of Beverage Alcohol. Washington DC

Mahmud, Lilyan 2015. Evaluasi prosedur pemungutan cukai minuman beralkohol buatan dalam negeri pada kantor pengawasan dan pelayanan bea dan cukai tipe madya pabean c manado. Jurnal Emba Volume 3 No. 1

Ismitania, 2012. Analisis pelekatan pita cukai MMEA buatan dalam negeri. Jakarta. FE UI Mardiasmo (2016:62) Perpajakan Edisi Revisi. ANDI.Yogyakarta

Muljono, Djoko 2014. Akuntansi Pajak. Jakarta. Salemba Empat.

Rahadian, 2015. Evaluasi kebijakan pengawasan pelekatan pita cukai pada minuman Mengandung etil alkohol (MMEA) buatan dalam negeri (studi pada kantor pengawasan dan pelayanan (kppbc) tipe madya cukai malang). Jurnal Perpajakan (JEJAK) Vol. 1 No. 1

Surono, 2012. Mengenal lebih dalam pungutan Cukai. Bahan ajar Teknis Cukai I. Tangerang : Sekolah Tinggi Akuntansi Negara

Sugiyono, (2015). Metode Penelitian Pendidikan. Bandung: Alfabeta.

UU No. 39 Tahun 2007 tentang Cukai 